\title{
Agricultural Knowledge Management System Development for Knowledge Integration
}

\author{
Dejen Alemu \\ Addis Ababa University \\ dejenfasil@gmail.com
}

\author{
Murray E. Jennex \\ San Diego State University \\ mjennex@mail.sdsu.edu
}

\author{
Temtem Assefa \\ Addis Ababa University \\ temtim@yahoo.com
}

\begin{abstract}
Agricultural KMS development involves various participants from different communities of practice (CoPs) who possess their own knowledge. However, the current development of technology neglected the local communities who possess indigenous knowledge, which is the key success factor for agricultural development. This study aims at contributing in the discourse on how to integrate scientific and $I K$ in agricultural KMS development and use. An interpretive analysis of primary qualitative data acquired through in-depth semi-structured interviews and participant observations was carried out following system development action research approach. The research result yields concepts for understanding the process conceptual framework in KMS development and use for knowledge sharing and integration.
\end{abstract}

\section{Introduction}

Literature is rich with the potential of ICTs as enabler for sustainable socio-economic development [1]. The applied technological advancements and developed tools are potentially capable of supporting the agricultural sector and smallholder farmers [2]. However, their use and relevance are still alien to the local rural communities [2]. Agricultural knowledge management systems are, therefore, unsuccessful to provide the full promised potential of ICTs in developing countries [1], [2]. Knowledge has also been recently receiving much attention as the basic enabler for the sustainable development and innovation [3]. Consequently, the notion of knowledge creation, capturing, and sharing has been repetitively raised by research and development organizations in their efforts to transform the Ethiopian and other developing countries agricultural sector. However, most of the current knowledge management (KM) and KMS development approaches focuses only on scientific knowledge, while overlooking the roles of indigenous knowledge (IK) contained by local communities.
The weak linkages between the scientific and indigenous knowledge are compounded by the historically marginalization of IK from the modern scientific community [4], [5]. Such approaches, thus, correspond and respond poorly to farmers' needs and expectations [5]. Hence, it is arguable that following such approaches of knowledge trend can led to solutions that do not fit the realities in the content. This circumstance has led to growing interest in the importance of IK and incorporation of it with scientific knowledge in KMS development and use in order to fit IT systems to users' needs [1], [2].

It is generally accepted that IK plays a crucial role in the developing countries agricultural production systems. However, IK is no longer reliable on its own which necessitates its integration with scientific knowledge and techniques for the enhancement of the agricultural sector [2], [6]. In agricultural KMS development, integration of indigenous knowledge with scientific knowledge is a critical success factor [1], [2]. This research, thus, focuses on understanding the sharing and construction of integrated diversity of knowledge as their integration would achieve more than either in their separation, whereby the full promised potential of ICTs in agricultural KMS development can be provided. Despite the fact that the integration of scientific and IK can be expected to improve agricultural productivity, yet there is no clearly developed framework demonstrating how the two can be integrated in a KMS development process. Thus, the study aims at contributing in the discourse on how to best integrate scientific and IK in agricultural KMS development and use. Besides to the theoretical understanding, this research also addresses the design tasks faced by practitioners. The solution of the real problem must be developed and evaluated the use of it using the appropriate criteria within socio-technical design science [7], [8]. Accordingly, this research in action further seeks the understanding of the KMS development and use in order to create the appropriate technological artifact for supporting the knowledge sharing and integration in agriculture. The present 
research is, therefore, driven by the following main research question:

How can the indigenous knowledge be best integrated with the mainstream of scientific knowledge in agricultural KMS development and use?

\section{Literature review}

Davenport and Prusak [9] [page 5] defined knowledge as "an evolving mix of framed experience, values, contextual information and expert insight that provides a framework for evaluating and incorporating new experiences and information". Knowledge is a crucial organizational asset but often it is a resource difficult to access that is challenging to share, imitate, buy, sell, store, or evaluate [10]. This is due to organization's knowledge is mainly embedded in the minds of its members, working routines and processes, organizational rules, practices, and norms [10], [11]. Jennex [10] stated that, in order to make knowledge repository useful, it must capture and store the context. It is, hence, crucial to understand knowledge with its context to facilitate the knowledge capturing from its source in agricultural development and making it available for reuse.

Knowledge created and used in agricultural sector falls into two categories: scientific and indigenous knowledge. Scientific knowledge includes all methods and practices driven by theoretical models and governed by testing of hypotheses and experimentation [12]. While IK is the knowledge and experience applied by local people passed over generations through trial and error locally with long histories of close interaction with the natural environment across cultures and geographical spaces [4], [13]. It has long been used as the basis for local-level decision making in agriculture, art and craft, communication and entertainment, traditional medicines and healing, education, and other vital socio-economic activities in many parts of the world [3], [13]. However, much of the IK are yet hardly explored and remains invisible; in turn, there is a grave threat to the extinction of IK [2], [3]. Thus, urgent actions are needed for systematic documentation and management of IK as the failure in the management of IK may slow down the rural development.

Knowledge loss is a big challenge for organizations as the economy grows due to the loss of knowledge holders, failure to capture critical knowledge, failure of knowledge repositories and forgetting [10]. The main challenge in all organizations is to efficiently discover knowledge, create new knowledge, capture, store, share, and apply it in order to gain competitive advantage. As such, $\mathrm{KM}$ is one that has come to be used to refer to explicit strategies, tools, and practices applied by management that seek to make knowledge as a resource for the organization. Jennex [14] defined KM as the practice of selectively applying knowledge from previous experiences of decision making to current and future decision making activities with the express purpose of improving the organization's effectiveness. The purpose $\mathrm{KM}$ is to understand, focus on, and manage systematic, explicit, and deliberate knowledge building and application, that is, manage effective knowledge processes and to renew knowledge constantly. The knowledge management function in the organization operates KM processes (i.e., knowledge creation, storage, sharing, and application), develops methodologies and systems to support them, and motivates people to participate in them [15]. The major challenges of $\mathrm{KM}$ are the process of knowledge capturing, integration, and sharing.

Previous researches such as Jennex [7] and Jennex and Olfman [8] have suggested that the KM activities need to be supported through KMS in order to foster the organization effectiveness. A KMS, a class of information systems (IS), is a managerial, technical, social, and organizational system structured to support the implementation of $\mathrm{KM}$ within an organization thereby enables organization to manage knowledge effectively and efficiently [17]. A KMS can be seen as an activity system that involves people making use of objects such as tools and technologies to create artifacts and products that represent knowledge in order to achieve a shared goal [11] [page 167]. It is not, therefore, the technology that distinct KMS from other type of IS; however, it is the highly involvement of human activity in their operation and designed to put organizational participants in contact with recognized experts in a variety of topic areas [15].

Web 2.0 tools are today widely used to develop an online KMS to understand users' interaction for knowledge sharing and integration [18]-[20]. Web 2.0 refers to a set of Web-based technologies such as wiki, blogs, content aggregators, social networking sites, podcasting, and other emerging forms of participatory applications and social media [18], [20], [21]. Web 2.0 tools are characterized by being user-centered, enhance social network formation, promote communication, interaction, and collaboration, and harness collective intelligence [21]; thereby help to systematize the processes of knowledge sharing, creation, and integration. For example, social networking tool can be used for connecting people and locate each other with similar interest; Wiki for collaborative, mediated, content production and organization; blogs enable user to subscribe to a blog and post comments in an interactive format; and real time collaboration tools to provide real time voice communication for interaction and knowledge sharing. These tools are important for 
supporting KM processes including explicit knowledge publishing and the tacit knowledge extraction, dissemination, integration, and utilization across various CoPs having common interest.

\section{Theoretical framework}

For understanding the integration of knowledge in agricultural KMS development, the theory of situated learning within community of practice (CoP) [22] was selected. The theory helps in creating a social infrastructure and view knowledge as socially constructed rather than viewing knowledge as an objective entity. Situated learning is conceptualized as the social context of learning in CoPs and defined as an informal aggregation of individuals engaged in common enterprise and distinguished by the manner in which its members interact and share interpretations [22], [23]. According to Karner et al [24], interaction and informal learning in $\mathrm{CoP}$ are critical for tacit knowledge capturing, sharing, and integrating with the codified knowledge. In agricultural KMS development, IK having the tacit format possessed by the local communities needs to be captured and integrated in the system. The theory of situated learning within CoP [22], thus, provides the concept of knowledge brokering important for understanding knowledge integration across CoPs.

Brokering denotes the activities of individuals that involves facilitating connections, bringing new ideas in and from the outside, and the sharing of knowledge between CoPs across knowledge boundaries [22]. Knowledge brokers bridge a gap in social organization and support knowledge exchange across knowledge boundaries through enhancing translation, coordination, alignment, and negotiation between different members from different CoPs perspectives [23], and thereby to facilitate and promote transaction between previously separated practices [25]. In the Ethiopian agricultural extension system, there are a group of people named extension agents who are responsible for knowledge and technology transfer to farmers from research. Hence, this research is interested to investigate the roles and practices of extension agents as knowledge brokers in order to understand their contribution in knowledge exchange among relevant CoPs in agricultural KMS development and use.

The research also draws theoretical attention to the other concept called boundary objects. They are any objects that are relevant to the practices of multiple communities, but they may be used and viewed differently by each of CoPs [26], and supporting collaboration, interaction, and knowledge sharing between CoPs within differing perspectives across social and geographical boundaries [1]. However, relatively few studies have investigated how they function in knowledge exchange. Members from different social groups use shared boundary objects for their interactions. IS professionals who develop and support the agricultural KMSs are, therefore, to learn the work practices and objects of each user community. Thus, in the development of agricultural KMS, system developers should involve boundary objects possessed by relevant CoPs in particular local communities in turn the shared KMS as a boundary object enables all relevant participants coming from different CoPs to interact and collaborate for their common practice. As such, this research is also interested in identifying the boundary objects possessed by different relevant social groups.

Several researches further suggested to investigate dynamics technological artifact as boundary object through designing and using the technology for knowledge sharing and knowledge integration [27]. System development (SD) is, thus, an important practice and research area in understanding the development of the technological artifact through bridging the gap between the technological and the social sides of it. According to Burstein and Gregor [28], the crucial role of SD is the result of the fact that the developed system can serve both as a proof-ofconcept for the fundamental research and provide a technological artifact that becomes the focus of expanded and continuing research. The development and the use of technological artifact as a boundary object can also be used to prove the concepts within socio-technical design science [7] for knowledge sharing and integration.

KMS development for knowledge sharing and integration requires an active participation of users not only in the design of the KMS but also in the use of KMS [29]. Technological artifact such as a shared KMS is not only created and changed in the design of it by human action, but also in the use of it to perform some activity [30]. Orlikowski [30] described it as duality of technology consisting of the design and use of time of the technological artifact. Accordingly, this research seeks to understand the design of the technological artifact as a boundary object relying on the roles and practices and boundary objects of different relevant CoPs in agricultural KMS. This in line with the first components of Orlikowski's (1992, p. 409) model (i.e., “technology as a product of human action”). Then, the developed technology artifact as a boundary object will serve as a medium for the communication and interaction of members coming from different CoPs [30]. Consequently, the research investigates how the shared technology artifact and knowledge brokering is 
significant for knowledge sharing and integration by relevant social groups through observation. Figure 1 depicts the process conceptual framework of the study using the situated learning in communities of practice [22], [23] and structurational model of technology by Orlikowski [30] for understanding knowledge sharing and integration in agricultural KMS development and use.

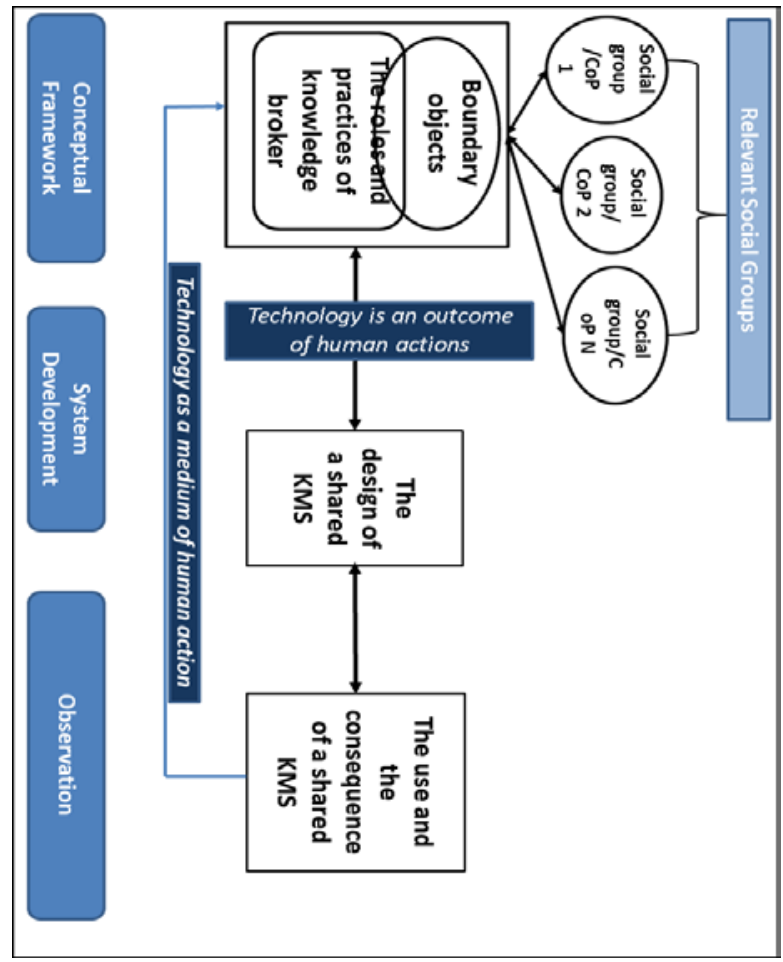

Figure 1. A process conceptual framework for agricultural KMS development and use.

\section{Research methodology}

This research follows qualitative interpretive paradigm [32] for better understanding of the integration of variety of knowledge. Nevertheless, understanding concepts merely are not enough in IS research, but system must also be implemented to measure the underlying concepts, thereby to guarantee its sustainability [28]. This research is, therefore, applied system development action research approach. Accordingly, the multi-methodological approach to IS in action research perspective which consists of four strategies: theory building, experimentation, observation, and system development is employed (see also Figure 2). In the first phase, the initial conceptual framework was drawn from the extant literature. Then, the framework further developed empirically. The proposed experimented conceptual framework leads to the development of a technological artifact (i.e., a KMS) with the intention of illustrating the conceptual framework [28]. Finally, the developed system is observed in practice for understanding its use and consequence by members from the relevant social groups.

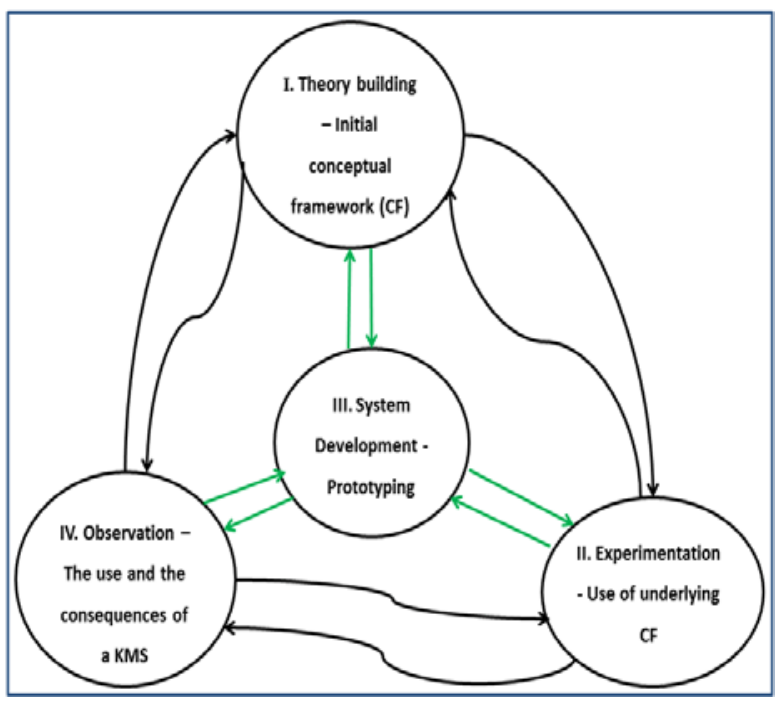

Figure 2. A Multi-methodological Approach to Information Systems Research Adapted from Burstein and Gregor [28].

An agricultural KMS development at an agricultural transformation agency (ATA) provides a theoretically relevant organizational setting for this investigation due to the presence of different groups of participants. Data were collected from local people from two districts of North Gondar Zone of Amhara Regional State of Ethiopia. Primary data were collected by employing indepth semi-structured interviews and participant observations. Of the total 23 informants, five were agricultural researchers, three technologists, eight extension agents, and seven farmers. The research subjects were selected based on their knowledge and experience. Even though the size of the sample is not large, it is the depth that matters because the researchers were able to keep asking until no new data emerged. Data were immediately transcribed using respondents' own words as fast as possible. Data collection and interpretive analyses were carried out side-by-side [33]. Through the iterative process of data collection and analysis following the multi-methodological approach to IS, the initial concepts were expanded and revised and then used to create a prototype KMS.

\section{Result and discussion}


The research has identified three different social groups in the agricultural KMS development: agricultural researchers, extension agents, and local farmers. Agricultural researchers possess scientific knowledge arises from their educational background, findings of researches and their everyday institutional practices. Local farmers are important source of IK and also use the scientific knowledge and technology from research. However, the KMS development process relies on data extracted from scientific experts and data generated on the basis of recognized scientific principles, draw upon spatial inputs derived mainly from the interpretation of remotely sensed satellite data. This research understood the potential of IK to bring the full potential of the KMS in agriculture and the development needs to blend indigenous and scientific knowledge. In the Ethiopian agricultural extension system, there are extension agents who are transferring knowledge and technology from research to local farmers. The research empirically investigated the roles and practices of extension agents as knowledge brokers.

\subsection{The roles and the practices of extension agents}

Extension agents in the current agricultural extension system are assumed to play a role in knowledge and technology transfer from research to local communities. There is a gap in agricultural development about the roles and the practices of extension agents as knowledge brokers for knowledge integration in KMS development and use. Accordingly, the research result yields concepts on the roles and practices of extension agent as a knowledge broker for knowledge sharing and integration in agricultural KMS development and use.

5.1.1. In-betweenness of extension agents. The study revealed that extension agents are positioned between agricultural researchers and local farmers and facilitate the knowledge exchange. Extension agents are learning about knowledge and technology from research through training and documents. Then, they teach and consult local farmers at their district. As such, they need to be well positioned to sustain an open and twoway communication with farmers through participating and interacting with them in all levels of agricultural development and KMS development [34]. As such, they can learn from local communities, educate them and engage with them at the requirement elicitation or needs assessment, planning, designing of KMS, implementation, usage, and evaluation levels.
5.1.2. Enhance participation. An extension agent as a knowledge broker is vital in blending different separate $\mathrm{CoPs}$ in agriculture through crossing the knowledge boundaries. They need to cross the boundaries of the local farmers to encourage them to participate and interact with them. Moreover, ability to listen farmers, giving value to farmers' insights and encouraging their decision making are critical in order to strengthen the participation of local farmers. Accordingly, they could facilitate the interaction of members coming from different $\mathrm{CoPs}$ and motivate them to participate by crossing the knowledge boundaries and engaging to educate and learn from them in turn exchange knowledge and technology. However, extension agents need to get permission to cross different relevant CoPs both informal local groups and formal social groups [25]. This role of knowledge brokering, therefore, requires special qualities of credibility and legitimacy of extension agents in order to cross different social groups [34] and should take an impartial position.

5.1.3 Network formation. The information from indepth interviews indicated the role of extension agents in developing and maintaining relationships among farmers and with other different CoPs through building of a network. During the implementation and planning of agricultural development, extension agents identify and bring people together. In Ethiopia, there are also several types of informal groups in which people gathered together at the community level, for example, funeral groups ('idir'), work sharing groups ('jigie'), and savings and loan-type groups ('iquob'). These groups create an important entry point for and promote linkages to outside actors and serve as a mechanism for transferring knowledge and technology. Extension agents often closely work with such informal networks to strengthen the link between individuals in a CoP. Networking among participants from heterogeneous CoPs can enable to incorporate collective actions [25]. Fostering the network of informal groups and the formal groups as a social, institutional, and technical process is crucial for interactive learning [35], thereby encourages knowledge sharing and integration.

\subsubsection{Knowledge and technology translation.} Extension agents translate knowledge and technology from research into different local contexts, and vice versa. Extension agents act as translators, in framing elements of the world view of scientific research in terms of the perspective of local communities. They translate the knowledge and technology from research into another language. Additionally, agents explain how the new knowledge and technology are adopted and implemented in the local farming practices. For this purpose, they understand the local farming context 
to interpret and apply the new knowledge and technology into the local context. This role of extension agents is not only to translate knowledge from research to farmers but also the vice versa. This is in-line with the argumentation that bi-directional knowledge translation between research and local communities are critical for knowledge integration [25].

\subsubsection{Coordinate collaboration and negotiation.} Agricultural development is complex problem that requires collaboration and negotiation among various dynamic social groups for developing solutions [35] Extension agents provide conducive environment through coordinating the collaboration and negotiation among relevant participants. They facilitate who and how people work together and negotiate for problem solving, encourage people to contribute knowledge and reflect on others idea, and assist individuals and groups to engage them in a dialogue during the problem solving process. In particular, extension agents can eliminate the farmer group problem of participation through enhancing a two-way communication with other scientific social groups. Extension agents assist participants to engage in a communicative dialogue and the development of consensus about the action to be taken to negotiate on the scope of the problem to be addressed and consensual solution. In sum, knowledge building and the deep shared understanding are best promoted when the collaboration and negotiation are facilitated through brokers in a dialogic nature.

\subsection{Boundary objects}

Informants from researchers and extension agents subjects reported a wide range of boundary objects for knowledge sharing among others, ISs, audio visual, guidelines, procedure, system documentation, report printout, publication, newsletter, bulletin, user training manuals, websites, and ICT Kiosks. Local farmers employ observation, traditional music and ceremonies, symbols, farming materials, storytelling, oral expressions, and oral mapping for indigenous knowledge sharing which serve as boundary objects. However, such boundary objects for sharing IK are not considered in the development of agricultural KMS and the KMS does not fully enable farmers to use the knowledge from it and to contribute their own. Consequently, the result of the research implicates the development of a shared KMS through involving the roles and boundary objects of all relevant social groups.

5.2.1. Designing of KMS as a boundary object. The KMS needs to support the different participants including extension agent as a knowledge broker, local rural communities, and agricultural researchers. To this effect, critical components of the shared KMS for knowledge sharing and integration are identified relaying on the roles and practices of relevant social groups and boundary objects. Following the terminologies presented by Saade et al [36] and Jung et al [37], three basic subsystems of KMS were identified: the people subsystem, the resource subsystem, and technological subsystem.

In building this research, the human subsystem includes local farmers, agricultural researchers, and extension agents, who are the core of the agricultural KMS. In order to share and integrate knowledge, active participation and collaboration among these social groups are highly critical in the KMS development process. Hence, development of the KMS was carried out by paying attention to those people. Table 1 indicated the human agents and their roles in the development of agricultural KMS. The resource subsystem consists of knowledge resources from the local and scientific communities and rules including guidelines and procedures for social interaction in agricultural system development. The KMS also consists of technological artifact and processes used by users from different social groups to support KM activities [8]. To this effect, the implementation subsystem is primarily concerned with the identification and development of applications for supporting $\mathrm{KM}$ activities in particular knowledge sharing and integration.

Table 1. The roles of relevant social groups in KMS development

\begin{tabular}{|c|c|}
\hline Social Groups & Roles \\
\hline $\begin{array}{l}\text { Agricultural } \\
\text { Researchers }\end{array}$ & $\begin{array}{ll}\text { - } & \text { Scientific knowledge } \\
& \text { systems creation, } \\
& \text { recreation, and } \\
& \text { presentation } \\
\text { - } & \text { Use IK from local farmers } \\
& \text { for further research } \\
\text { - } \quad \text { Interact with extension } \\
\text { agents } \\
\text { Evaluate the ongoing } \\
\text { implementation of new } \\
\text { knowledge and technology }\end{array}$ \\
\hline Local farmers & $\begin{array}{l}\text { - Indigenous knowledge } \\
\text { creation, recreation and } \\
\text { presentation } \\
\text { Use scientific knowledge } \\
\text { and technology from } \\
\text { research } \\
\text { Interact with extension } \\
\text { agents and researchers }\end{array}$ \\
\hline
\end{tabular}




\begin{tabular}{ll}
\hline Extension & Extension agents exchange \\
agents as & knowledge and technology between \\
knowledge & farmers and researchers. \\
brokers & \\
\hline
\end{tabular}

Web 2.0 tools were used to develop a tailorable technological artifact in order to understand actionable changes to KMS function or content [29] for knowledge sharing and integration. Web 2.0 tools were employed in this study to provide various ways of interaction among people to share users contributed contents, develop content collection by user community, and to create and modify artifacts for content contribution and interaction. The Web 2.0 tools were selectively employed in various ways with the corresponding $\mathrm{KM}$ activities in particular for knowledge sharing and integration. Additionally, the selection process involved the needs, skills and expectations of relevant CoPs members in agricultural KMS.

5.2.2. The use of KMS as a boundary object. We provided access to 20 informants from local farmers, agricultural researchers, and extension agents to an online KMS following its development from February 2017 to April 2017, who were voluntary to participate in the research. Finally, participants are observed while using the system and further interviewed the informants for understanding of the significance and the consequence of a shared KMS as a boundary object.

During the use of the online KMS, we observed the communication and participation of participants from local communities and research groups who are located in distant and geographically disparate locations. Their communication and interaction employed several forms such as text-based (chat), voice and video communication through instant messaging, audio and video conferencing, and podcasting. As such, the attractiveness of these Web 2.0 tools lies in the direct contact between participants whereby highly decrease the feeling of distance among them. Moreover, audio and video communication and mapping in the KMS foster the externalization of indigenous tacit knowledge from local farmers through visualization. The shared KMS is highly important not only to reach geographically disparate users and enhance the interaction between researchers, extension agents and farmers but also provides a distributed environment to disseminate knowledge in all directions instantly. The use of the KMS can also eliminate the existing hierarchical structure of the country extension system, which promotes one-way knowledge and technology dissemination from research to local farmers.
The participants from the rural communities and agricultural researchers access the existing knowledge, enriching dialogue/forum to enhance interaction, contribute their knowledge and create new knowledge. Knowledge contents presented in different languages (i.e., farmers' local language) and presentation of content in different forms (i.e., textual, image, audio, and video) enables farmers and others to easily access information and be able them to interact. Farmers share their own knowledge (i.e., indigenous knowledge) using oral mapping, storytelling, and observation. Hence, audio blogging and podcasting, instant message, and visualization tools employed in the KMS help farmers to access knowledge from others and share their own.

The online KMS enables users to connect with others informally in their CoPs and with other users from different CoPs. The social network tools in the shared KMS also enable them to identify the knowledgeable and interact on one-to-one, one-tomany, and many-to-many among users from different CoPs independent of the existing hierarchical structure of the extension systems. Such networking is important for exposing users to different knowledge. Consequently, users from different groups highly communicate, interact and collaborate for their common interest, whereby, knowledge sharing and integration are enhanced. Some of the comments from users of the KMS boundary object:

The system is now easy for us to use. I join extension agents and agricultural researchers who can help me through providing information. I also received updates through the system. (Farmer-Respondent \#14)

Many of the farmers have a difficulty to read textual contents from the website. However, this website provides information in different forms especially audio and visual format. As a consequence, farmers can listen audio contents and see images and videos, thereby they interact each other and with other CoP. (Extension-Agent-Respondent \#8)

I can access information in different forms such as textual, audio, image, and video in my own language (i.e., Amharic language). I can also share my own to others. (Farmer-Respondent \#7)

An online shared KMS enables us to foster communication and interaction of users from different social groups desperate geographically. (ExtensionAgent-Respondent \#9)

Farmers and extension agents can easily communicate and interact with us by using this KMS. It is very important for us to reach many extension agents and farmers. Consequently, the usage of it can avoid the existing hierarchical structure, thereby to exchange knowledge between farmers and research. (Agricultural-Researcher-Respondent \#5) 
It is now easy for us and even for farmers in our kebele to use this system and to perform our roles of knowledge brokering and use knowledge from different sources from it. This is because the system is accessible in our local language, have user friendly interface, and it provides different contents and functionalities relevant for our roles of knowledge transfer. (Extension-Agent-Respondent \#4)

5.2.3. The consequence. The roles of extension agents as knowledge brokers and a shared KMS as a boundary object have brought the consequences for knowledge sharing and integration including,

- Knowledge sharing among participants from different CoPs and

- New knowledge creation through integration.

The shared KMS developed using Web 2.0 tools with knowledge brokering activities support furtherreaching and more innovative to connect with a large number of users from different CoPs. The mediators (KMS and broker) aid users to accelerate the flow and reach of divergent knowledge. As this study demonstrated, the mediators foster the externalization of tacit knowledge since it promotes the participation of all relevant users and enables them to interact and collaborate with each other. As a result, users contribute their knowledge and experience. Especially local farmers share their indigenous knowledge to other members of CoPs. The interaction among participants from different CoPs enables users to share their knowledge and experience. Knowledge with tacit format can be shared among participants, convert tacit knowledge to explicit knowledge and preserve diverse knowledge systems in the repository, and moving it to the other formal and informal groups.

The knowledge boundary that exists across different occupation groups become an opportunity to integrate knowledge [22], [38] through the interplay of mediators and a KMS. The interplay of the mediators creates an ongoing two-way communication and interaction across participants from different CoPs. Users from different groups are exposed to diverse knowledge and linked to key knowledge resources. Consequently, users can access knowledge from different sources, reflect on others thought, and learn from others in turn knowledge from different sources can be integrated.

\section{Conclusion}

In order to share and integrate knowledge, it is critical to identify the relevant social groups, their information needs and the knowledge they possess. In the case of agricultural KMS development, the research identified social groups who possess different knowledge who are capable of influencing the KMS development and use. In this research, there are local farmers who possess IK and agricultural experts who possess scientific knowledge. However, result of this research indicated that knowledge in agriculture have been applied in an isolated and fragmented manner. Despite many challenges in the integration and sharing of knowledge, their amalgamation can be expected to bring agricultural productivity.

The study investigated the roles and practices of extension agents as knowledge brokers for knowledge sharing and integration in KMS development and resulted in five themes. Consequently, the roles and practices of extension agents as knowledge brokers can have a potential to bridge the knowledge boundaries through exchanging knowledge among participants. As a result, relevant organizations are required to give attention to the roles and practices of extension agents as knowledge brokers to enhance the knowledge management activities. However, understanding the roles of brokering is not only enough to understand knowledge sharing and integration, but there is also a need to investigate the role of boundary objects.

Despite the fact that several boundary objects are identified in the agricultural KMS development process; boundary objects employed by local farmers for IK sharing, preservation, and integration are not considered in the current KMS development process. In response, a shared KMS for knowledge sharing and integration is designed to address the challenges raised by diverse groups of participants. The research demonstrated the use of a shared KMS by a large number of users coming from diverse CoPs in a distributed environment. Thus, a shared boundary objects should be flexible to be used by different participants to promote communication, interaction, and collaboration among relevant participants for knowledge sharing and integration.

The interplay of a shared KMS and the roles of knowledge brokers can allow users to access diverse knowledge and an efficient exchange of different forms of knowledge. Additionally, the interplay of mediators can create highly participative, collaborative, and negotiation culture, which are critical for knowledge sharing and integration in turn owners of the problem can collectively solve their problem. Consequently, knowledge sharing among participants from different CoPs and new knowledge creation through the integration of the existing knowledge are highly fostered. Despite the fact that the roles of knowledge brokers and boundary objects are the central point for knowledge sharing and integration, the existing hierarchical structure requires 
restructuring to support brokering and a shared KMS as a boundary object.

The contributions of the research include theoretical, methodological, and practical implications. Theoretically, the study can advance the literature on the roles and practices of agricultural experts as knowledge brokers and a shared KMS as a boundary object for knowledge sharing and integration. It can also contribute in extending the theory of situated learning in community of practice [22], [23] and the Orlikowski's structuration model of technology [30] for understanding knowledge sharing and integration in KMS development and use.

The methodological implication of this research is two-fold: understanding of the application of systems development action research approach on the one hand and in extending the design science approach, on the other. It is significant for investigating the requirement through theoretical understanding, further important to examine how technological artifact is designed, and also enables to understand the use and the consequences of the technological artifact, whereby a comprehensive conceptual framework for KMS development can be coined. Therefore, the research contributes methodologically for the use of system development for a complete understanding of a complex research area such as KMS and DSS. In addition, it can also contribute in extending the design science approach coined by Hevner and his colleagues [39] for understanding the use and the consequences of the KMS. Hevner's et al. [39] approach assumed the design of information systems is completed before it is placed in use context and engaged by users [29]. However, users can also influence the technological artifact while using the system through knowledge sharing and modifying the technology. This research can, therefore, contribute in extending the design science approach in an understanding of the participation of end users in the use time of the technological artifact.

Practically, the research can provide management understanding in developing strategies and utilizing for the potential of extension agents as knowledge brokers for knowledge sharing and integration. It can also provide management insight on the roles of boundary objects and Web 2.0 tools for KM activities and KMS development ultimately to support marginalized and poor smallholder farmers.

Finally, while the developed shared KMS boundary object appears to be successful, future research will be necessary to ensure the sustainability of the system.

\section{References}

[1] S. K. Puri, "Integrating scientific with indigenous knowledge: constructing knowledge alliances for land management in India,” MIS Q., vol. 31, no. 2, pp. 355-379, 2007.

[2] M. Masinde, "Survivability to sustainability of biodiversity: what do ICTs and indigenous knowledge have to do with it?,” 2013. [Online]. Available: http://dx.doi.org/10.1145/2517899.2517900. [Accessed: 13Oct-2014].

[3] J. K. Sarkhel, "Strategies of indigenous knowledge management in libraries," Qual. Quant. Methods Libr., vol. 5, pp. 427-439, 2016.

[4] World Bank, "Integrating the indigenous knowledge of Borana pastoralists into rangeland management strategies in Southern Ethiopia,” 2005. [Online]. Available: http://www.worldbank.org/afr/ik/default.htm. [Accessed: 22Oct-2014].

[5] UNDP, "Promoting ICT based agricultural knowledge management to increase production and productivity of smallholder farmers in Ethiopia," UNDP Ethiopia's Development Brief Series. 2012.

[6] E. C. Kipkorir, C. K. Songok, and E. M. Mugalavai, "Integration of indigenous knowledge systems in climate change adaptation and enhancing food security in Nandi and Keiyo districts, Kenya.," in Experiences of Climate Change Adaptation in Africa, Climate Change Management, 2011, pp. 69-95.

[7] S. Miah, J. Gammack, and D. Kerr, “A socio-technical approach to designing and evaluating industry oriented applications,” Electron. J. Inf. Syst. Eval., vol. 15, no. 2, pp. 163-175, 2012.

[8] M. E. Jennex and L. Olfman, "Development recommendations for knowledge management/organizational memory systems," in Contemporary Trends in Systems Development, Springer US, 2001, pp. 209-222.

[9] T. H. Davenport and L. Prusak, Working knowledge. Boston, MA: Harvard Business School Press, 1998.

[10] M. E. Jennex, "A proposed method for assessing knowledge loss risk with departing personnel," VINE J. Inf. Knowl. Manag. Syst., vol. 44, no. 2, pp. 185-209, 2014.

[11] K. Dalkir, Knowledge management in theory and practice. Burlington: Elsevier Butterworth-Heinemann, 2005.

[12] N. Tripathi and S. Bhattarya, "Integrating indigenous knowledge and GIS for participatory natural resource management: state-of-the-practice," Electron. J. Inf. Syst. Dev. Ctries., vol. 17, no. 3, pp. 1-13, 2004.

[13] C. Lanzano, "What kind of knowledge is 'indigenous knowledge'? critical insights from a case study in Burkina Faso,” Transcience, vol. 4, no. 2, pp. 3-18, 2013. 
[14] M. E. Jennex, "What is knowledge management?," Int J. Knowl. Manag., vol. 1, no. 4, pp. i--iV, 2005.

[15] W. R. King, "Knowledge management and organizational learning,” Ann. Inf. Syst., vol. 4, pp. 3-13, 2009.

[16] M. E. Jennex, S. Smolnik, and D. Croasdell, "The search for knowledge management success," in Hawaii International Conference on Systems Sciences, 2012.

[17] A. Arisha and M. A. F. Ragab, "Knowledge management and measurement: a critical review," J. Knowl. Manag., vol. 17, no. 6, pp. 873-901, 2013.

[18] Z. Gaál, L. Szabó, N. Obermayer-Kovács, and A. Csepregi, "Exploring the role of social media in knowledge sharing," Electron. J. Knowl. Manag., vol. 13, no. 3, pp. 185-197, 2015.

[19] M. E. Jennex, "Knowledge management in support of education,” J. Adm. Dev., vol. 1, no. 2, pp. 15-28, 2007.

[20] U. Sivarajah, Z. Irani, and V. Weerakkody, "Evaluating the use and impact of Web 2.0 technologies in local government,” Gov. Inf. Q., vol. 32, pp. 473-487, 2015.

[21] W. Wang, R. Xiong, and J. Sun, "Design of a Web 2.0based knowledge management platform," in Integration and innovation orient to E-society, W. Wang, Ed. Boston: Springer, 2007, pp. 237-245.

[22] J. Lave and E. Wenger, Situated learning: legitimate peripheral participation. Cambridge UK: Cambridge University Press, 1991.

[23] E. Wenger, Communities of practice: learning, meaning and identity. Cambridge UK: Cambridge University Press, 1998.

[24] S. Karner, H. Rohracher, B. Bock, F. Hoekstra, and H. Moschitz, "Knowledge brokerage in communities of practice: synthesis report on literature review," in Foodlinks, EU 7th Framework, 2011.

[25] R. Kislov, P. Wilson, and R. Boaden, “The 'dark side' of knowledge brokering,” J. Health Serv. Res. Policy, vol. 0, no. 0, pp. 1-6, 2016.

[26] C. Rosenkranz, H. Vranesic, and R. Holten, "Boundary interactions and motors of change in requirements elicitation: a dynamic perspective on knowledge sharing," J. Assoc. Inf. Syst., vol. 15, no. 6, pp. 306-345, 2014.

[27] N. Levina and E. Vaast, “The emergence of boundary spanning competence in practice: implications for implementation and use of information systems," MIS Q., vol. 29, no. 2, pp. 335-354, 2005.
[28] F. Burstein and S. Gregor, "The systems development or engineering approach to research in information systems: an action research perspective," in Proceedings of 10th Australasian Conference on Information Systems, Wellington NZ 1-3 December 1999, School of Comms \& Info Mgmt Vic Uni of Wellington, Wellington NEW ZEALAND, 1999, pp. 122-134.

[29] M. Germonprez, D. Hovorka, and U. Gal, "Secondary design: a case of behavioral design science research," $J$. Assoc. Inf. Syst., vol. 12, no. 10, pp. 662-683, 2011.

[30] W. J. Orlikowski, "The duality of technology: rethinking the concept of technology in organizations," Organ. Sci., vol. 3, no. 3, pp. 398-427, 1992.

[31 W. J. Orlikowski, "Using technology and constituting structures: a practice lens for studying technology in organizations," Organ. Sci., vol. 11, no. 4, pp. 404-428, 2000 .

[32] H. K. Klein and M. D. Myers, "A set of principles for conducting and evaluating interpretive field studies in information systems," MIS Q., vol. 23, no. 1, pp. 67-93, 1999.

[33] G. Walsham, "Interpretive case studies in IS research: nature and method,” Eur. J. Inf. Syst., vol. 4, no. 2, pp. 7481, 1995.

[34] J. Hellin, "Agricultural extension, collective action and innovation systems: lessons on network brokering from Peru and Mexico,” J. Agric. Educ. Ext., vol. 18, no. 2, pp. 141159, 2012.

[35] A. Koutsouris, "Exploring the emerging intermediation roles (facilitation and brokage) in agricultural extension education," in International Conference - Emerging Horizons of Agricultural Extension for Sustainable Rural Development, 2014, pp. 21-37.

[36] R. Saade, F. Nebebe, and T. Mak, "Knowledge management systems development: theory and practice," Interdiscip. J. Information, Knowledge, Manag., vol. 6, pp. 35-72, 2011.

[37] J. Jung, I. Choi, and M. Song, “An integration architecture for knowledge management systems and business process management systems," Comput. Ind., vol. 58, pp. 21-34, 2007.

[38] P. R. Carlile, “Transferring, translating, and transforming: an integrative framework for managing knowledge across boundaries,” Organ. Sci., vol. 15, no. 5, pp. 555-568, 2004.

[39] A. R. Hevner, S. T. March, J. Park, and S. Ram, "Design science in information systems research," MIS Q., vol. 28, no. 1, pp. 75-105, 2004. 